\title{
EFFECT OF HIBISCUS SABDARIFFA LINN ON IL-6 AND TNF- $\alpha$ LEVELS IN OVERTRAINED RAT HEART
}

\section{DEWI IRAWATI SOERIA SANTOS0 ${ }^{*}$, SRI YUNITA ${ }^{2,3}$, NURUL PARAMITA1,TRINOVITA ANDRAINI', NENG TINE KARTINAH ${ }^{1}$, GUSHAN FAHMI EL BAYANI' ${ }^{1}$, ERMITA I. IBRAHIM ILYAS ${ }^{1}$}

\author{
1Department of Medical Physiology, Faculty of Medicine Universitas Indonesia, Jakarta, Indonesia, ${ }^{2}$ Master Program in Biomedical \\ Sciences, Department of Medical Physiology, Faculty of Medicine Universitas Indonesia, Jakarta, Indonesia, ${ }^{3}$ Faculty of Medicine and \\ Health Science, Universitas Bengkulu, Bengkulu, Indonesia
}

Email: dewi.irawati@ui.ac.id

Received: 15 Dec 2018, Revised and Accepted: 10 Mar 2019

\begin{abstract}
Objective: This study aims to determine the effect of Hibiscus sabdariffa Linn. (HSL) administration on the interleukin-6 (IL-6) and tumor necrosis factor $\alpha$ (TNF- $\alpha$ ) levels in rat heart. Overtraining was proven to increase the IL- 6 and TNF- $\alpha$ levels in the blood, and HSL had anti-inflammatory and anti-oxidant properties. However, no studies have been conducted on the effect of methanolic extract of HSL administration on the IL- 6 and TNF- $\alpha$ levels in overtrained rat heart.
\end{abstract}

Methods: This study used 25 male adult Wistar rats aged 8-10 w and weighing 200-250 g. The rats were randomly divided into five groups: control (C), control H. sabdariffa Linn (C+HSL), overtraining (OT), overtraining H. sabdariffa Linn (OT+HSL), and aerobic (A). Treatment was given 5 times a week for $11 \mathrm{w}$. At the end of the study, the IL- 6 and TNF- $\alpha$ levels were measured using a standard ELISA kit.

Results: IL- 6 and TNF- $\alpha$ levels in the heart were the highest in the overtraining group. The group that received HSL administration showed the lowest TNF- $\alpha$ and IL-6 levels.

Conclusion: HSL could be a used to protect the heart from an inflammatory state, particularly in an overtraining condition.

Keywords: Overtraining, Interleukin-6, Tumor Necrosis Factor-alpha, Hibiscus sabdariffa Linn

(C) 2019 The Authors. Published by Innovare Academic Sciences Pvt Ltd. This is an open access article under the CC BY license (http://creativecommons. org/licenses/by/4. 0/) DOI: http://dx.doi.org/10.22159/ijap.2019.v11s6.33535

\section{INTRODUCTION}

Competitive athletes train to improve their performance by increasing training load combined with an adequate recovery period. However, if the excessive training load is not accompanied by an adequate recovery period, an abnormal training response may occur and a state of overreaching and overtraining may develop. Overreaching is the accumulation of training and/or non-training stress that results in a short-term decrement in performance capacity with or without related the physiological and psychological signs and symptoms of maladaptation; the restoration of performance capacity may take from several days to several weeks. Conversely, overtraining (OTS) is the accumulation of training and/or non-training stress that results in a long-term decrement in performance capacity with or without the related physiological and psychological signs and symptoms of maladaptation; the restoration of performance capacity may take several weeks or months $[1,2]$.

OTS is an extreme condition of maladapted physiology. The symptoms of OTS are varied, and they include fatigue, depression, bradycardia, loss of motivation, insomnia, irritability, agitation, tachycardia, hypertension, restlessness, anorexia, weight loss, lack of mental concentration, stiff muscles, anxiety, and awakening unrefreshed [3]. In mice, OTS led to left ventricular hypertrophy and increased gene expression related to pathological hypertrophy, such as mRNA for the ANP, mRNA for $\beta$-myosin heavy chain, and mRNA for skeletal muscle actin [4].

The exact etiology and pathogenesis of OTS are actively being investigated. Numerous hypotheses on the pathophysiology of OTS have been proposed. OTS has been assumed to result from the decrement of muscle glycogen level (glycogen hypothesis), increase in serotonin level in the brain that causes central fatigue (central fatigued hypothesis), decrement in plasma glutamine level (glutamine hypothesis), oxidative stress, autonomic nervous system imbalance, alterations in the hypothalamic-pituitary-adrenal and hypothalamicpituitary-gonadal axes, and local inflammation response accompanied with an increased cytokine level (cytokine hypothesis) [3].
In the cytokine hypothesis, training causes degrees of micro trauma to the muscle, connective tissue, and/or bones and joints. This trauma produces a mild inflammatory response with the final purpose of adaptive healing. However, with a continuous high load of training without an adequate resting period, the local acute inflammation becomes chronic, the cytokine released in this process activates the circulating monocyte, and a systemic inflammation with OTS symptoms occurs. The cytokines central to the OTS are the proinflammatory interleukin-1 $\beta$ (IL-1 $\beta$ ) and tumor necrosis factor $\alpha$ (TNF- $\alpha$ ). Aside from IL- $1 \beta$ and TNF- $\alpha$, IL- 6 also plays an important role in OTS. IL-6 has both pro inflammatory and anti-inflammatory effects [5].

IL-6 is a pleiotropic cytokine that bridges the innate and adaptive immune systems [6]. In the heart, the IL-6 family signaling on the cardiac myocyte is cardioprotective during the acute response. However, when this cytokine remains elevated chronically, it can induce maladaptive hypertrophy and decreases contractile function. Increased IL-6 production is associated with depressed cardiac function. Acutely, the IL- 6 family cytokine protects myocytes against oxidative stress, and its signaling induces an anti-apoptotic program. However, the IL-6 family signaling also depresses the basal contractility of myocytes and the beta adrenergic responsiveness of the cells, leading to a decreased function. The IL- 6 family signaling also induces gene expression in the myocytes associated with pathological hypertrophy [7].

Cardiac cells secrete TNF- $\alpha$ as an inflammatory response to stress. TNF- $\alpha$ triggers intra-cellular signaling cascades that modulate host defense against injury, facilitate growth and survival, and promote apoptosis and matrix metalloproteinase expression [8]. Circulating and cardiac TNF- $\alpha$ levels are elevated in heart diseases, such as dilated cardiomyopathy, myocardial infarction, and left ventricular (LV) pressure overload. Consequently, TNF- $\alpha$ has been implicated in the pathogenesis of ventricular remodeling in infarcted heart and in cardiac dysfunction. TNF- $\alpha$ contributes to adverse left ventricular remodeling during pressure overload through the regulation of cardiac repair and remodeling, leading to ventricular dysfunction [9]. 
Hibiscus sabdariffa Linn (HSL) is a medicinal and food plant rich in phytochemical compounds, which are the source of its biological properties. HSL has cardioprotective and anti-inflammatory activities in the heart, ear, and hippocampus [10-12]. HSL also has antioxidant, anti-nociceptive, anti-diarrheal, antibacterial, antifungal, anti-parasitic, antipyretic, hepatoprotective, nephronprotective, cancer-preventive, and anti-diabetic activities [12, 13]. HSL contains several phytochemical compounds, including organic acids, phenolic acids, anthocyanin, flavonoids, trace elements, and vitamins. Flavonoid quercetin inhibits the TNF- $\alpha$ gene expression by modulating the NF- $\kappa \beta$. However, there is no evidence yet suggesting the effect of HSL on IL- 6 and TNF- $\alpha$ levels in rat heart in the overtraining condition. In this study, we investigated the effect of HSL extract on the IL- 6 and TNF- $\alpha$ levels in overtrained rat heart.

\section{MATERIALS AND METHODS}

\section{Experimental animals}

This experimental in vivo study used 25 male adult Wistar rats (Rattus norvegicus) aged $8-10 \mathrm{w}$ old and weighed $200-250 \mathrm{~g}$. All the rats were from PT Bio Farma (Persero), Bandung, Indonesia. The rats were maintained in individual cages in the FKUI laboratory under a controlled temperature $\left(22 \pm 2^{\circ} \mathrm{C}\right)$ on a $12: 12 \mathrm{~h}$ light-dark inverted cycle. Food and water were provided ad libitum. The experimental procedures were approved by the ethics committee of the Medical Research-Faculty of the Medicine Universitas Indonesia/Cipto Mangunkusumo Hospital (FMUI/RSCM) No: 0955/UN2. F1/ETIK/2018. The rats were randomly divided into five groups: control (C, sedentary), control $H$. sabdariffa ( $\mathrm{C}+\mathrm{HSL}$, sedentary, given $H S L$ methanolic calyx. extract), aerobic (A, mild aerobic protocol), overtraining (OT, overtraining protocol), and overtraining $H S L(\mathrm{OT}+\mathrm{HSL}$, overtraining protocol, given $H$. sabdariffa calyx methanolic) group.

\section{Training protocols}

Before entering the physical exercise program, the exercising groups $(\mathrm{A}, \mathrm{OT}$, and $\mathrm{OT}+\mathrm{HSL})$ followed an adaptation procedure with low speed and duration of running until the rats were accustomed to run on the treadmill.

The protocol used for overtraining was adapted from Hohl [14]. The overtraining program consists of 11 experimental weeks, with consecutive days of training sessions followed by $2 \mathrm{~d}$ of recovery, and is divided into the adaptive training phase 1 (AT1), adaptive training phase 2 (AT2), and incremental training phase (T2X, T3X, and T4X). AT1 was conducted for $4 \mathrm{w}$ with a progressive increase in speed and duration. Then, in AT2, the running speed and the duration that were reached at the end of AT1 were maintained for $4 \mathrm{w}$ to reach adaptation at a stable training load. AT1 and AT2 were performed during the daytime between
13:00 and 17:00. A 24-h recovery time was given between training sessions. In the last $3 \mathrm{w}$ of training, the frequency of daily exercise sessions was increased to two (T2X), three (T3X), and four (T4X) times with the AT2 training load. During this period, recovery time was also reduced between training sessions $(4,3$, and $2 \mathrm{~h}$, respectively) to cause an imbalance between overload and recovery. T3X and T4X were performed during an extended daytime period between 10:00 and 17:00. The amount of training in minutes was individually quantified in each training session [14].

In the aerobic experimental group, the rats were subjected to $11 \mathrm{w}$ of training session, twice a week, at the same duration and velocity of running $(12 \mathrm{~m} / \mathrm{mins}$ for $10 \mathrm{~min})$.

\section{HSL extract}

The methanolic calyx extract of HSL was obtained from the Central Laboratory of Medicinal Studies Institut Pertanian Bogor (Bogor, Indonesia) with $86.34 \%$ purity. The extract was administered orally at a dose of $500 \mathrm{mg} / \mathrm{kg} \mathrm{BW}$ at 5 times a week for $11 \mathrm{w}$. Its administration to the overtraining and mild aerobic groups was conducted $3 \mathrm{~h}$ before physical exercises.

\section{Heart extraction and biochemical assay}

After $11 \mathrm{w}$ of treatment, the rats were sacrificed by decapitation. Thoracotomy was performed, and the heart was removed and then directly stored at $-80{ }^{\circ} \mathrm{C}$. The heart tissue was then homogenized according to the instruction of the IL- 6 and TNF- $\alpha$ ELISA kit manufacturer. The total protein of the tissue homogenate was measured using the Bradford method. The measurement of IL- 6 and TNF- $\alpha$ levels was performed using a commercial kit from Elabscience (Hubei, China) with catalog no: E-EL-R0015 and E-ELR0019 for IL- 6 and TNF- $\alpha$, respectively. The concentrations of IL-6 and TNF- $\alpha$ were presented in pg per $\mu \mathrm{g}$ of the total protein.

\section{Statistical analysis}

The results are expressed as the mean \pm standard error of the mean. The data were normally distributed. One-way analysis of variance (ANOVA) with a significance level of 0.05 was used for statistical analysis, and Tukey's test was used for pairwise comparisons.

\section{RESULTS}

\section{Overtraining obtained the highest level of IL-6 in rat heart}

No significant difference in the IL-6 level among the groups was found. Nevertheless, the overtraining group $(67.2 \pm 14.42 \mathrm{pg} / \mathrm{mg})$ obtained the highest IL- 6 level in comparison with the aerobic $(57.37 \pm 8.338 \mathrm{pg} / \mathrm{mg})$ and the two control groups $(\mathrm{C}=32.34 \pm 8.67$ and $\mathrm{C}+\mathrm{HSL}=32.97 \pm 4.097 \mathrm{pg} / \mathrm{mg}$, respectively), as shown in fig. 1 .

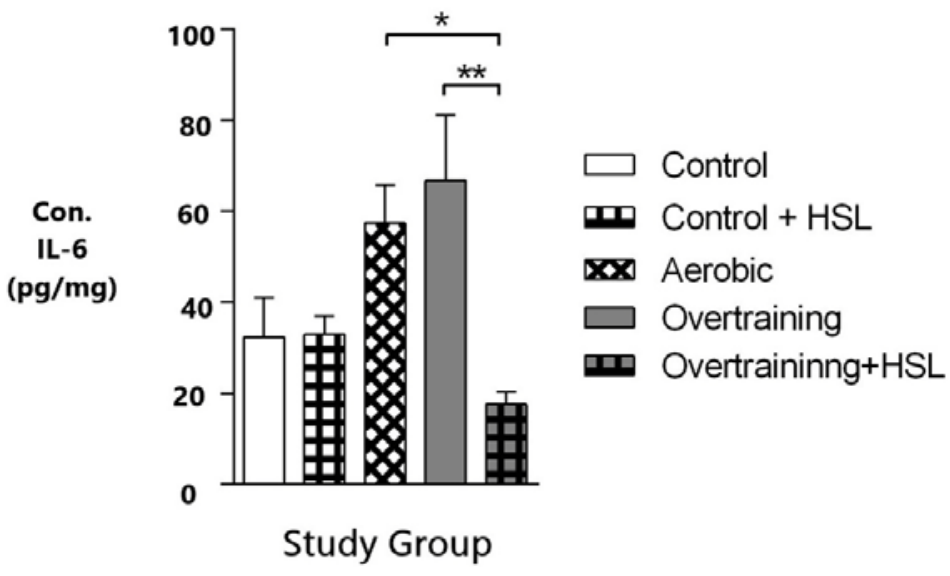

Fig. 1: IL-6 level in rat heart

Overtraining and aerobic training obtained the highest level of TNF- $\alpha$ in rat heart

The overtraining group $(206.7 \pm 40.96 \mathrm{pg} / \mathrm{mg})$ exhibited a significantly higher $(p<0.05)$ TNF- $\alpha$ level compared with the $C$ group
$(93.03 \pm 20.23 \mathrm{pg} / \mathrm{mg})$ and the C+HSL group $(93.19 \pm 10.72 \mathrm{pg} / \mathrm{mg})$. The level of TNF- $\alpha$ in the aerobic group $(162.2 \pm 17.31 \mathrm{pg} / \mathrm{mg})$ was not significantly different compared with that in the C and C+HSL groups. 
Overtraining with the administration of HSL Linn produced lower TNF- $\alpha$ and IL-6 levels than overtraining only

The level of IL- 6 in the OT+HSL $(17.62 \pm 2.612 \mathrm{pg} / \mathrm{mg})$ group was lower than that in the OT group $(6.72 \pm 14.42 \mathrm{pg} / \mathrm{mg})$. This level of IL6 was more than threefold lower than that in the OT group and was statistically significant $(\mathrm{p}<0.006)$. Interestingly, the OT+HSL group $(17.62 \pm 2.612 \mathrm{pg} / \mathrm{mg})$ also had a lower IL-6 level than the aerobic group $(57.37 \pm 8.338 \mathrm{pg} / \mathrm{mg}, \mathrm{p}<0.03)$. A similar observation was found in the TNF- $\alpha$ level. The OT+HSL group $(44.95 \pm 6.252 \mathrm{pg} / \mathrm{mg})$ had a lower TNF- $\alpha$ level of up to twofold than the OT group $(206.7 \pm 40.96 \mathrm{pg} / \mathrm{mg})(\mathrm{p}<0.001$, fig. 2$)$.

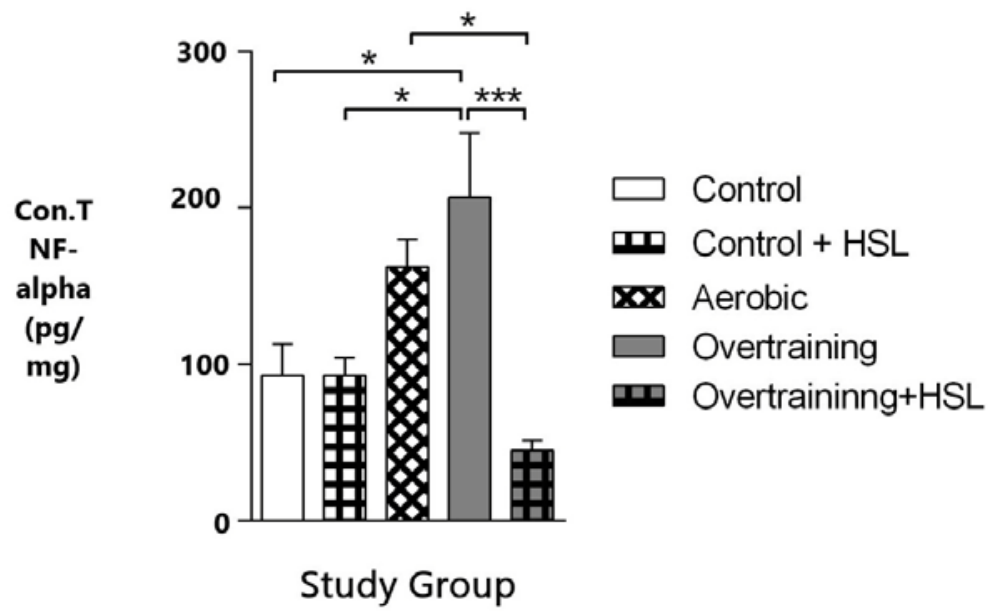

Fig. 2: TNF- $\alpha$ level in rat heart

\section{DISCUSSION}

This study showed that overtraining increased the TNF- $\alpha$ level and tended to increase the IL-6 level in the heart, consistent with other studies $[4,15,16]$. Overtraining has been proved to induce acute local inflammation, which may develop into chronic inflammation, thus producing systemic inflammation. The cytokines involved in this process are IL-1 $\beta$, TNF- $\alpha$, and IL-6 [17].

The expression of TNF- $\alpha$, which is a cytokine that is produced in cardiac myocytes, smooth muscle cells, and endothelial cells in response to endotoxin independent of inflammatory cells in ex vivo and in vitro cardiac studies [18], was up-regulated in isolated cardiac myocytes and fibroblast following experimental ischemia and myocardial infarction. It was also up-regulated in response to pressure overload and stretch in isolated cardiac myocytes [19]. The cardiac-restricted over-expression of the secreted and transmembrane form of TNF- $\alpha$ was shown to induce cardiac myocyte hypertrophy and the re-expression of the fetal gene program. TNF- $\alpha$ also reduced myocardial contractility. TNF- $\alpha$ induced apoptosis in cardiac myocytes, which contribute to the progressive LV wall thinning and adverse cardiac remodeling [20]. Thus, we assumed that the marked increase in TNF- $\alpha$ level in overtraining could cause a pathologic phenomenon, such as the morphological and functional alteration of the heart.

Conversely, IL-6 is a pleiotropic cytokine that is produced not only by immune cells and immune accessory cells, including monocytes and macrophages but also by cardiovascular components, such as endothelial cells, vascular smooth muscle cells, and ischemic myocytes. Increasing the IL-6 and IL-6R levels contributes to the signaling pathway, leading to cardiac hypertrophy [21]. IL-6 has been shown to depress papillary muscle contraction and is negatively inotropic in cardiomyocyte cultures. High IL-6 concentrations usually precede the development of multi-organ failure in patients with cardiogenic shock due to acute myocardial infarction, dilated cardiomyopathy, and valvular heart disease [22]. In our study, overtraining only tended to increase the IL-6 level in rat heart. Nevertheless, TNF- $\alpha$, which is the other inflammation cytokine, increased robustly and should be enough to cause a negative effect on the heart.

Thus, we administrated HSL extract for the overtraining condition and found that this extract prevented the increase in the IL- 6 and TNF- $\alpha$ levels in rat heart. This result supports those of previous studies elucidating the anti-inflammatory effect of HSL [10, 23]. The suppression of IL- 6 and TNF- $\alpha$ production could be related to the quercetin and anthocyanin compounds in HSL. Quercetin has been proved to have an inhibitory effect on IL-6 production through its effect on regulating the p38-mitogen-activated protein kinase (p38MAPK) [24]. Quercetin also suppresses the TNF- $\alpha$ gene and expression. The possible mechanism of this suppression may be mediated by downregulating the gene expression of NF- $\kappa \beta$ and decreasing the phosphorylation of Ік $\beta \alpha$ and Iк $\beta \beta$ by quercetin, thus suggesting that quercetin decreases the activation of NF- $\kappa \beta$ [25]. Anthocyanins, the other active compound of HSL, have antioxidant, anti-inflammation, and anti-cancer properties [26]. Anthocyanins inhibit the production of nitric oxide, prostaglandine E2, TNF- $\alpha$, and IL-6 in a dose-dependent manner without a cytotoxic effect. Kim et al. showed that anthocyanins decreased the reactive oxygen species production, thereby reducing the MAPK activation and inflammatory cytokine production [27]. Anthocyanins inhibit the translocation of $\mathrm{NF}-\kappa \beta$ from the cytosol to the nucleus and prevent the phosphorylation of I $\beta$, thus decreasing the production of proinflammatory mediators such as IL-6 and TNF- $\alpha$ [28].

In conclusion, this study demonstrates that overtraining along with the administration of HSL extract produces lower TNF- $\alpha$ and IL- 6 levels in rat heart than overtraining only. Therefore, HSL extract can be a promising natural compound candidate to protect the heart from a chronic inflammation state particularly caused by overtraining.

\section{ACKNOWLEDGMENT}

This article was presented at The $3^{\text {rd }}$ International Conference and Exhibition on Indonesian Medical Education and Research Institute (ICE on IMERI 2018), Faculty of Medicine, Universitas Indonesia, Jakarta, Indonesia. We thank the $3^{\text {rd }}$ ICE on IMERI Committee who had supported the peer review and manuscript preparation before submitting to the journal. The authors would like to thank Nurasi Lidya E. Marpaung for her technical assistance in the laboratory treatment.

\section{FUNDING SOURCE}

This study was funded by Hibah PITTA DRPM-UI 2018.

\section{ETHICS AND HUMAN AND ANIMAL EXPERIMENTATION}

The experimental procedures were approved by the Health Research Ethical Committee FKUI No: 0955/UN2. F1/ETIK/2018. 


\section{AUTHORS CONTRIBUTIONS}

All the author have contributed equally

\section{CONFLICT OF INTERESTS}

The authors declare no potential conflict of interest

\section{REFERENCES}

1. Meeusen R, Duclos M, Foster C, Fry A, Gleeson M, Nieman D, et al. Prevention, diagnosis, and treatment of the overtraining syndrome: joint consensus statement of the European college of sport science and the American college of sports medicine. Med Sci Sports Exerc 2013;45:186-205.

2. Kreher J. Diagnosis and prevention of overtraining syndrome: an opinion on education strategies. Open Access J Sport Med 2016;7:115-22.

3. Kreher JB, Schwartz JB. Overtraining syndrome: a practical guide. Sports Health 2012;4:128-38.

4. da Rocha AL, Teixeira GR, Pinto AP, de Morais GP, Oliveira L da C, de Vicente LG, et al. Excessive training induces molecular signs of pathologic cardiac hypertrophy. J Cell Physiol 2018;233:8850-61.

5. Smith LL. Cytokine hypothesis of overtraining: a physiological adaptation to excessive stress? Med Sci Sports Exerc 2000;32:317-31.

6. Jones SA. Directing transition from innate to acquired immunity: defining a role for IL-6. J Immunol 2005;175:3463-8.

7. Fontes JA, Rose NR, Cihakova D. The varying faces of IL-6: from cardiac protection to cardiac failure. Cytokine 2015;74:62-8.

8. Bradham WS, Moe G, Wendt KA, Scott AA, Konig A, Romanova $\mathrm{M}$, et al. TNF- $\alpha$ and myocardial matrix metalloproteinases in heart failure: relationship to LV remodeling. Am J Physiol Heart Circ Physiol 2002;282:H1288-95.

9. Sun M, Chen M, Dawood F, Zurawska U, Li JY, Parker T, et al. Tumor necrosis factor- $\alpha$ mediates cardiac remodeling and ventricular dysfunction after pressure overload state. Circulation 2007;115:1398-407.

10. Obouayeba AP, Meite S, Boyvin L, Yeo D, Kouakou TH, Guessan JDN. Cardioprotective and anti-inflammatory activities of a polyphenols enriched extract of Hibiscus sabdariffa petal extracts in Wistar rats. J Pharmacogn Phytochem 2015;4:57-63.

11. Fahmi G, Bayani EL, Marpaung NLE, Arnold D, Simorangkir S, Sianipar IR, et al. Anti-inflammatory effects of hibiscus sabdariffa linn. on the IL-1 $\beta /$ IL-1ra ratio in plasma and hippocampus of overtrained rats and correlation with spatial memory. Kobe J Med Sci 2018;64:73-83.

12. Ali MK, Ashraf A, Biswas NN, Karmakar UK, Afroz S. Antinociceptive, anti-inflammatory and antidiarrheal activities of ethanolic calyx extract of hibiscus sabdariffa Linn. (Malvaceae) in mice. J Chinese Integr Med 2011;9:626-31.

13. Da-Costa-Rocha I, Bonnlaender B, Sievers H, Pischel I, Heinrich M. Hibiscus sabdariffa L.-a phytochemical and pharmacological review. Food Chem 2014;165:424-43.
14. Hohl R, Ferraresso RLP, De Oliveira RB, Lucco R, Brenzikofer R, De Macedo DV. Development and characterization of an overtraining animal model. Med Sci Sports Exerc 2009;41:1155-63.

15. Lira FS, Rosa JC, Pimentel GD, Tarini VA, Arida RM, Faloppa F, et al. Inflammation and adipose tissue: effects of progressive load training in rats. Lipids Health Dis 2010;9:1-10.

16. Gholamnezhad Z, Hossein Boskabady M, Hosseini M, Sankian M, Khajavi Rad A, Rad KA. Evaluation of immune response after moderate and overtraining exercise in Wistar rat. Iran J Basic Med Sci 2014;17:1-8.

17. Dos Santos Cunha G, Ribeiro JL, De Oliveira AR. Overtraining: theories, diagnosis and markers. Rev Bras Med do Esporte 2006;12:267e-271e.

18. Giroir BP, Johnson JH, Brown T, Allen GL, Beutler B. The tissue distribution of tumor necrosis factor biosynthesis during endotoxemia. J Clin Invest 1992;90:693-8.

19. Sack MN. Tumor necrosis factor-a in cardiovascular biology and the potential role for anti-tumor necrosis factor-a therapy in heart disease. Pharmacol Ther 2002;94:123-35.

20. Hedayat M, Mahmoudi MJ, Rose NR, Rezaei N. Proinflammatory cytokines in heart failure: double-edged swords. Heart Fail Rev 2010;15:543-62.

21. Anda TK, Akahashi TT. Interleukin-6 and cardiovascular diseases. Japan Heart J 2003;45:183-93.

22. El-Menyar AA. Cytokines and myocardial dysfunction: state of the art. J Card Fail 2008;14:61-74.

23. Kao E, Hsu J, Wang C, Yang S, Lee H. Polyphenols extracted from hibiscus sabdariffa L. inhibited lipopolysaccharide-induced inflammation by improving antioxidative conditions and regulating cyclooxygenase-2 expression. Biosci Biotechnol Biochem 2014;73:385-90.

24. Liu J, Li X, Yue Y, Li J, He T, He Y. The inhibitory effect of quercetin on IL- 6 production by LPS-stimulated neutrophils. Cell Mol Immunol 2005;2:455-60.

25. Nair M, Mahajan S, Reynolds J, Aalinkeel R, Nair H, Schwartz S, et al. The flavonoid quercetin inhibits proinflammatory cytokine (tumor necrosis factor alpha) gene expression in normal peripheral blood mononuclear cells via modulation of the NF-к $\beta$ system. Clin Vaccine Immunol 2006;13:319-28.

26. Hartati FK, Widjanarko SB, Widyaningsih TD, Rifai M. Antiinflammatory evaluation of black rice extract inhibits TNF- $\alpha$ IFN- $\gamma$ and IL- 6 cytokines produced by immunocompetent cells. Food Agric Immunol 2017;28:1116-25.

27. Kim JN, Han SN, Ha TJ, Kim HK. Black soybean anthocyanins attenuate inflammatory responses by suppressing reactive oxygen species production and mitogen activated protein kinases signaling in lipopolysaccharide-stimulated macrophages. Nutr Res Pract 2017;11:357-64.

28. Kim HJ, Xu Lianji, Chang KC, Shin SC, Chung JI, Kang Dawon, et al. Anti-inflammatory effects of anthocyanins from black soybean seed coat on the keratinocytes and ischemia reperfusion injury in rat skin flaps. Microsurgery 2012;32:563-70. 